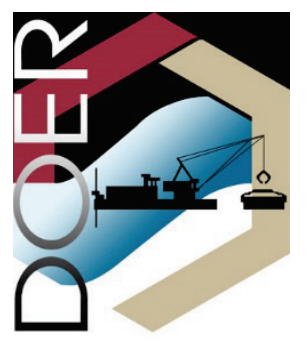

\title{
Atlantic Sturgeon Movements in Relation to a Cutterhead Dredge in the James River, Virginia
}

by Matthew Balazik, Safra Altman, Kevin Reine, and Alan Katzenmeyer

PURPOSE: This technical note describes a field study investigating the movements of federally endangered Atlantic sturgeon, Acipenser oxyrinchus oxyrinchus (ATS), during the summer and fall of 2017 near a cutterhead dredge working in the James River, Virginia, to provide data addressing the concern about the potential impacts of dredging activities (for example, excavation, transit, disposal, sounds, reduced water quality) on the ATS.

BACKGROUND: In 2012, the National Marine Fisheries Service (NMFS) declared that ATS distinct population segments (that is, regional subpopulations) were threatened or endangered throughout their range along the Atlantic coast (Figure 1, USA Federal Register 2012a, 2012b).

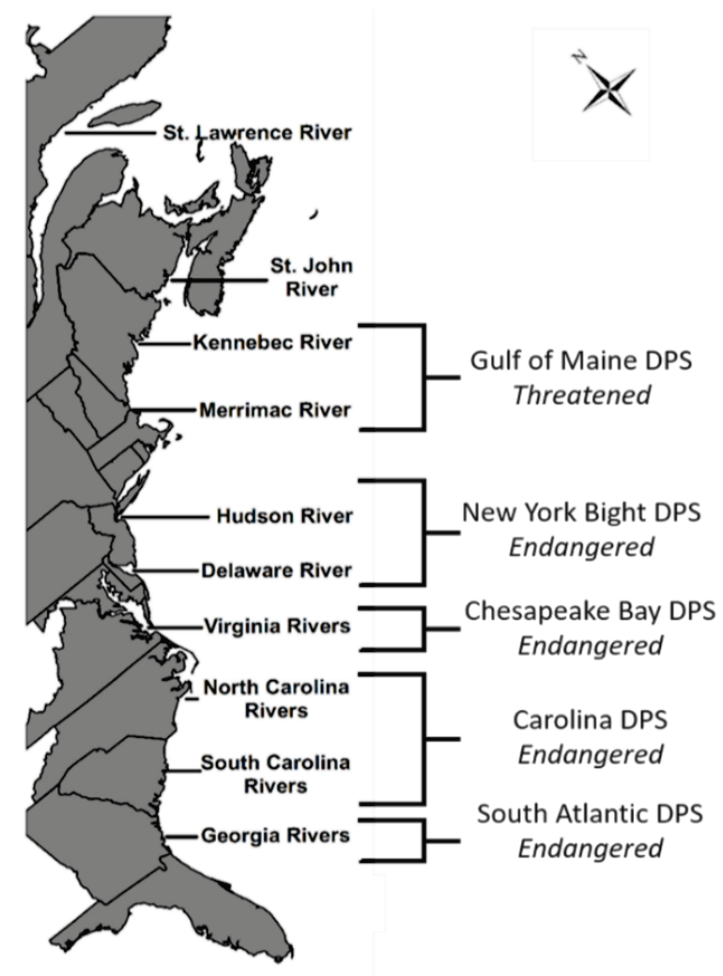

Figure 1. Federally endangered or threatened Atlantic sturgeon (ATS) populations as distinct population segments (DPS). The US Army Corps of Engineers (USACE) is responsible for maintaining navigation in all of these areas. 
Through the Coastal Zone Management Act ${ }^{1}$ (Public Law 92-583), many states have implemented time-of-year restriction windows on federal dredging projects, also known as environmental windows, with the intent to avoid potential dredge-related risks to sensitive biological resources or habitats (Reine, Dickerson, and Clarke 1998). Currently, states along the East Coast have established environmental windows for the spring ATS spawning migration. However, when environmental windows were implemented, it was thought that ATS spawning was limited to the spring season (Atlantic Sturgeon Status Review Team 2007). Since 2012, several studies have documented that ATS spawning occurs during both spring and fall within distinct river systems (James River, Virginia: Balazik, Garman, et al. 2012, Balazik and Musick 2015, Balazik et al. 2017; Roanoke River, North Carolina: Smith, Flowers, and Hightower 2015; Edisto River, South Carolina: Farrae, Post, and Darden 2017). The discovery of multiple spawning seasons has resulted in modifications to existing ATS population-monitoring strategies and has simultaneously raised concerns with state and federal agencies with respect to expansion of anadromous fish environmental windows into the fall months to protect fall run ATS.

Dredging is listed as a threat to ATS recovery (ASSRT 2007); however, there are limited data on the effects of dredging. Although Chapman et al. (2019) and Parsley, Popoff, and Romine (2011) describe movements of white sturgeon (A. transmontanus) and green sturgeon (A. medirostris) in relation to a dredge and sediment placement areas, data are limited on describing ATS movement near a dredge. A study by USACE showed that both passively (stationary receivers) and actively (followed by researchers on a boat) tracked subadult ATS survived when released within $200 \mathrm{~m}$ of an operating cutterhead dredge (Reine et al. 2014). ${ }^{2}$ However, until the current field study, no fine spatial-scale data existed characterizing ATS movements around an operating dredge. From an environmental window perspective, generating knowledge about the effects of dredging on the movement of ATS will help determine whether an environmental window in the fall season would be needed to protect ATS from dredging activities.

This technical note describes the results of the first field study using Vemco Positioning System (VPS) technology to determine how adult ATS migrating to a spawning habitat move around an active dredge. In addition to adult ATS behavior, this study also analyzed whether dredging operations had any noticeable effects on juvenile and subadult ATS feeding behavior.

ATS LIFE HISTORY: The ATS is anadromous and exhibits philopatric behavior (ASSRT 2007, 3; Hilton et al. 2016, 1). After hatching, the fish gradually move downstream towards the coast, where they mature over a span of several years. Age of maturity varies clinally, with southern populations maturing at younger ages than northern populations (Balazik et al. 2010; Balazik, Reine, et al. 2012; Hilton et al. 2016). Because ATS have disparate behaviors according to life stage, the species is typically separated into three different life-history categories: juvenile, subadult and adult (Hilton et al. 2016).

The ATS juvenile life stage is classified as fish that are beyond the yolk-sac stage but have not left their natal river (Hilton et al. 2016). In the James River, juvenile ATS typically leave the river at age two and are less than $50 \mathrm{~cm}$ fork length (FL). During the past decade, there seems to have been a

1. Coastal Zone Management Act of 1972, 16 U.S.C. $33 \S 1451$ et seq. (1747).

2. For a full list of the spelled-out forms of the units of measure used in this document, please refer to US Government

Publishing Office Style Manual, 31st ed. (Washington, DC: US Government Publishing Office, 2016), 248-52,

https://www.govinfo.gov/content/pkg/GPO-STYLEMANUAL-2016/pdf/GPO-STYLEMANUAL-2016.pdf. 
lack of spawning success in the James River (Matthew Balazik, Virginia Commonwealth University, unpublished data). Because the juvenile life stage is relatively short and the fish are challenging to collect in the James River, only three juveniles with active telemetry tags were at large during the study period. Because James River juveniles typically spend their entire first two years of life in tidal rivers, where dredging occurs almost year-round, managers are concerned about the potential negative impacts of dredging on this life stage, when the fish are most vulnerable.

Once a juvenile enters the ocean environment, it is classified as a subadult. Subadult ATS are sexually immature and roam along the coast (ASSRT 2007; Hilton et al. 2016). Subadults typically overwinter in coastal estuaries and the ocean and inhabit tidal rivers during the other seasons to feed. This pattern continues until the fish reach sexual maturity. Subadults that inhabit the James River are typically between 50 and $110 \mathrm{~cm}$ FL. Males in the James River population become sexually mature around 10 years of age and females around 15 years (Balazik, McIninch, et al. 2012). Because subadults spend most of the year in estuaries, managers are also concerned about the potential negative impacts of dredging operations on subadult ATS feeding behavior. Since 2012, the Virginia Institute of Marine Science (VIMS) has been catching and telemetering subadult ATS in the James River. During the study period, there were about 80 active telemetry tags in subadults. Subadults are known to disperse to non-natal estuaries, so many of the 80 telemetered fish will spend the spring-fall season in other estuaries. However, in previous years about half of the telemetered James River subadults returned to the James River to feed.

Adult ATS in the James River are typically $>140 \mathrm{~cm}$ FL (Balazik, McIninch, et al. 2012; Balazik 2015; Hilton et al. 2016). Adult ATS spend most of the year feeding in the ocean and only return to freshwater to spawn. Males usually spawn every year, while females spawn every $2-5$ years (ASSRT 2007; Balazik 2015; Hilton et al. 2016). As previously described, there are two separate spawning populations in the James River, spring and fall (Balazik, Garman, et al. 2012; Balazik and Musick 2015). Documentation of multiple spawning groups in other rivers is increasing along the fish's range. The spring spawning group was previously recognized and is already protected by environmental windows. Environmental windows are not in place for the more recently documented fall group, and managers are concerned that riverine dredging may hinder adult ATS spawning success. Virginia Commonwealth University (VCU) has been telemetering adult ATS in the James River since 2010 and had about 140 active tags during the study period. Typically over 100 telemetered fall adults annually enter the James River. Fall-spawning ATS usually stage in the lower part of the James River near river kilometer ( $\mathrm{rkm}$ ) 30, until water temperatures decrease below $28^{\circ} \mathrm{C}$ during August-September and then, move upstream of rkm 130 to spawn (Balazik 2015; Balazik and Musick 2015). This pattern means the adults must traverse dredging operations around $\mathrm{rkm} 55$ in the James River that typically occur annually from July through October.

\section{METHODS}

Study area. The study area is a $12 \mathrm{~km}$ reach of the federal navigation channel in a relatively broad, $>4 \mathrm{~km}$ wide, section of the James River in Virginia. Annual maintenance dredging commonly occurs between July and November. During the study, two portions of the $12 \mathrm{~km}$ stretch were dredged by the hydraulic-cutterhead dredge Lexington (Figure 2). The Lexington is $60.6 \mathrm{~m}$ long, $11.5 \mathrm{~m}$ wide, and $2.8 \mathrm{~m}$ draft barge dredge with a 2,000 $\mathrm{hp}(1500 \mathrm{~kW})$ pump attached to a 
$51 \mathrm{~cm}$ diameter intake pipe. The cutterhead had a diameter of $1.4 \mathrm{~m}$. The dredge's location was determined at 30 s intervals using the USACE Automatic Identification System Analysis Package (AISAP) tool. All dredged sediment was placed at a site located in the south of the navigation channel (Figure 2).

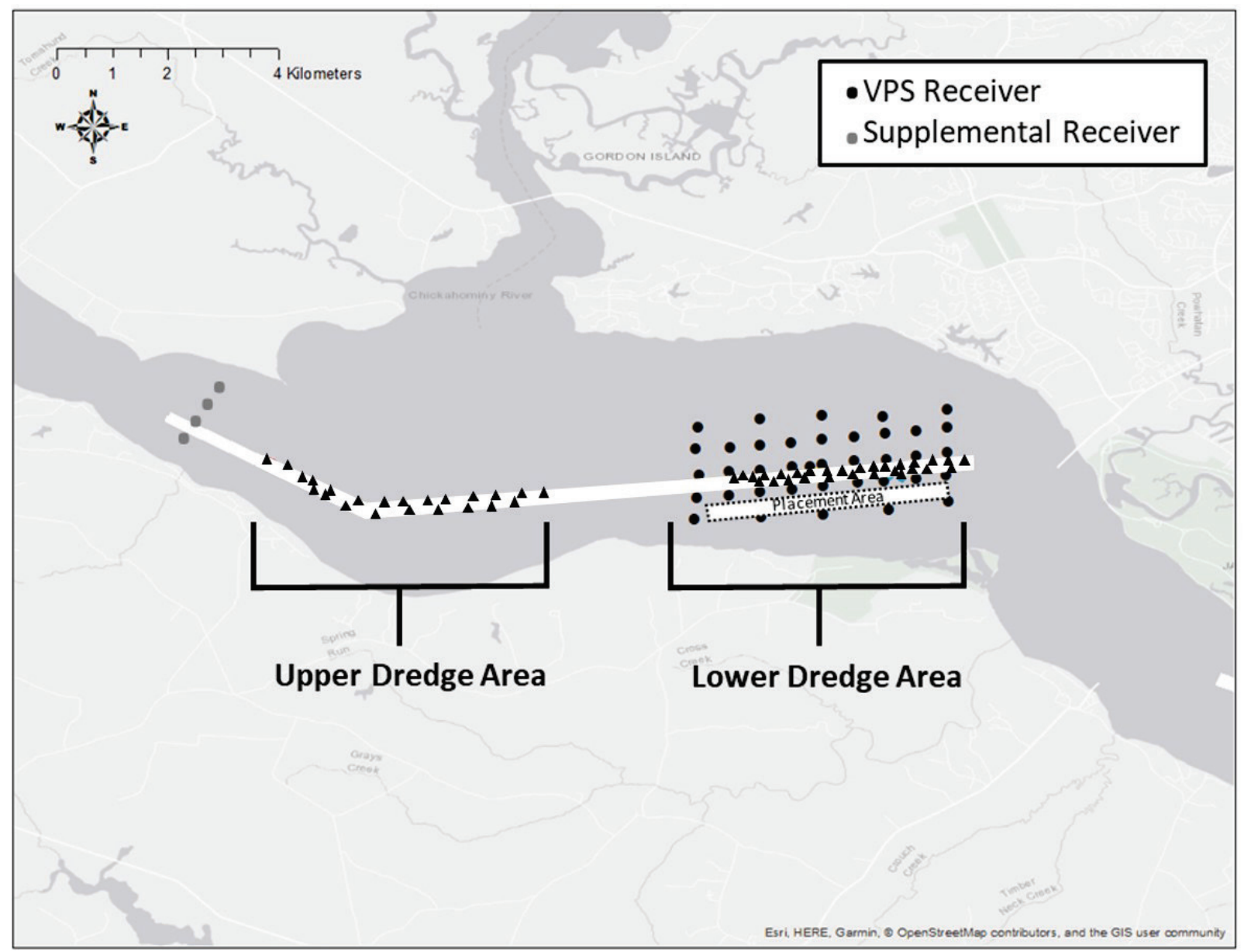

Figure 2. Map of study area. The white polygon extending through most of the figure is the maintained navigation channel. The points in the channel are dredge locations. The placement area polygon is where the lower dredge area sediment was placed. Black dots show the Vemco Positioning System (VPS) receiver locations while the grey points show where a supplementary gate was placed to provide some coverage for the upper dredge area.

Study animals. During previous years as part of endangered species recovery research, VCU and VIMS implanted Vemco telemetry tags bursting at $69 \mathrm{kHz}$ frequency into various-sized ATS throughout the James River (see Balazik 2015 for detailed methods). At the time of this project, there were about 140 adult, 80 subadult, and 3 juvenile telemetered ATS at large in the James River. ATS spawning occurs further upstream from the study area, in an area where the river is more narrow $(<200 \mathrm{~m}$ wide).

Acoustic telemetry. The VPS uses trilateralization technology to estimate down to $1 \mathrm{~m}$ spatial resolution of telemetered objects within a study area (Vemco 2013). This technique requires 
receivers to be strategically placed in a study area so that a single transition from the tagged target is detected almost simultaneously on three receivers (Figure 3). Using thedifference in arrival time to multiple receivers, the position of the tagged target can be estimated. The VPS receiver array was mounted near the bottom of the river on stands constructed of concrete. The stand consisted of a $1 \mathrm{~m}$ long by $10 \mathrm{~cm}$ diameter polyvinyl chloride (PVC) pipe positioned vertically with one end incorporated into a concrete base (61 length $\times 61$ width $\times 12 \mathrm{~cm}$ deep; about $45 \mathrm{~kg}$ ). Rebar cross members that extend about $45 \mathrm{~cm}$ from each direction of the slab were added to strengthen the concrete and to help keep the receiver stand stable. The VPS receiver was placed into the top of the PVC pipe with the hydrophone exposed to the water (Figure 4).

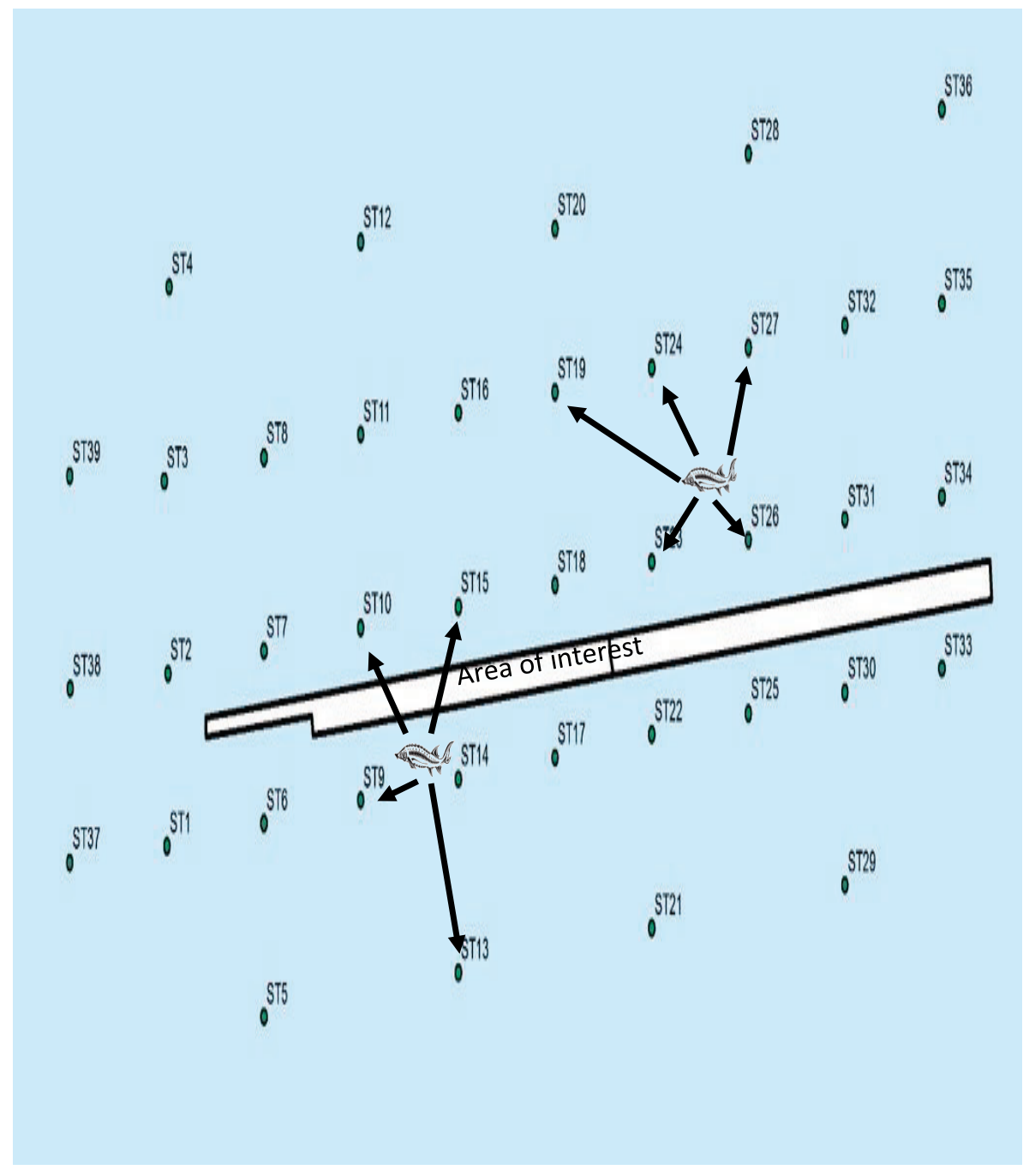

Figure 3. Conceptual drawing showing a VPS. The tagged object moves through an array specifically designed for the study area. When the tag transmits a signal various receivers detect the tag and varying times. Using trilateralization, also known as difference in arrival, the position of the organism can be determined at $1 \mathrm{~m}$ resolution. 


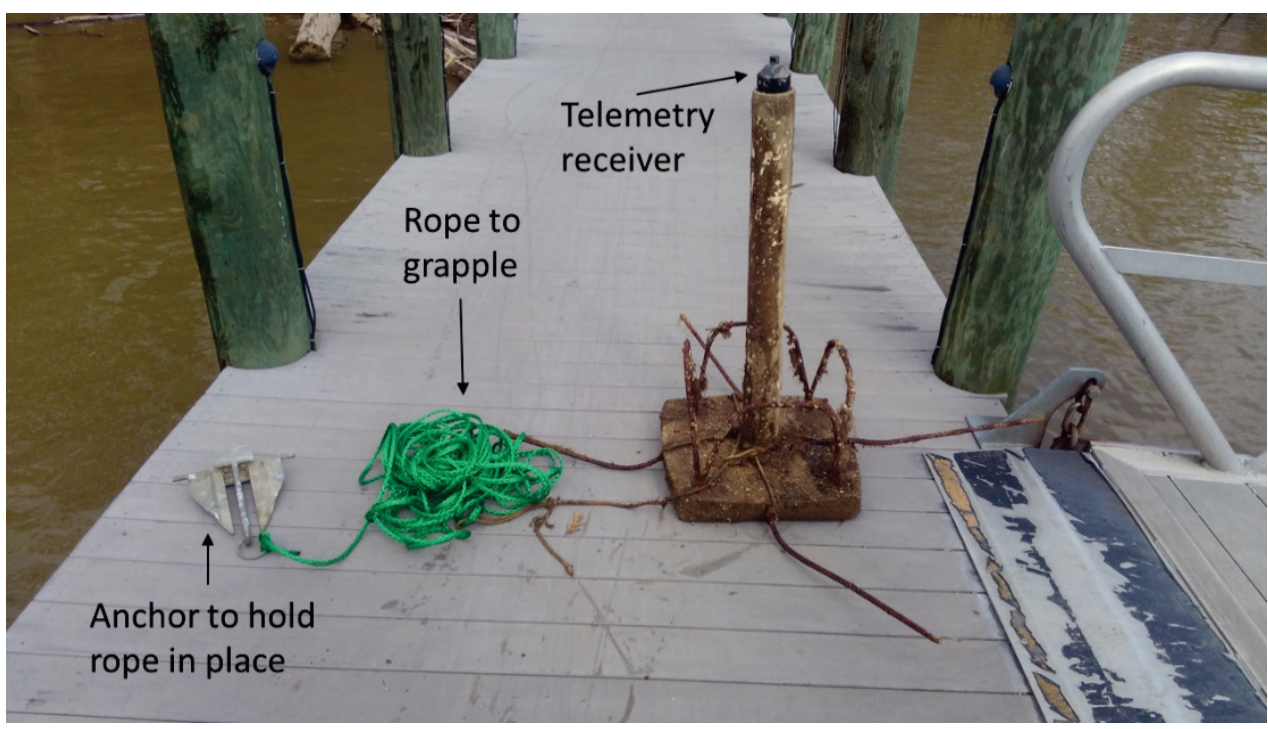

Figure 4. Receiver setup to reduce movements of receives in the VPS array. The rope allows the setup to be grappled for retrieval.

Rebar bent in a U-shape was incorporated into the base of the concrete to further strengthen the stand and provide lifting handles. A $30 \mathrm{~m}$ length of rope was fastened to the base of the stand to a $3 \mathrm{~kg}$ anchor. The rope allows the receiver setup to be removed using a grappling hook (Figure 4).

A 37 VPS receiver array with collocated synchronization tags was deployed at rkm 56 to monitor movements of tagged ATS in the lower dredge area (Figure 2). One reference tag was placed in the middle of the array to improve positioning data of the ATS (Figure 2). The VPS array deployment was initiated on July 20, 2017, completed on August 6, and generated data through October 29. VPS positions used for data analysis were vetted by only using positions estimated to be within the array grid. Positions were further vetted following methods by Roy et al. (2014) using horizontal positioning error scores. There were not enough receivers available to provide VPS coverage at the upper dredge area. A supplemental gate was placed on July 20 about $2 \mathrm{~km}$ upstream of the upper dredge area to provide extra coverage for when the dredge was working in this area (Figure 2). The supplemental receivers were affixed to the bottom with an $11 \mathrm{~kg}$ anchor. The supplemental gate could not determine fine-scale positions but could determine whether and when migrating adults were passing by the upper dredge area when the dredge was working in the upper area.

Acoustic telemetry analysis. The Optimized Hot Spot Analysis tool (ESRI ArcMap 10.5.1 Pro) was used to help determine the general paths and positions ATS took when moving through the study area. This technique uses inferential statistics and applies $z$ and $p$ scores to hexagon polygons using Getis-Ord Gi* Cluster Analysis (Getis and Ord 1992). The tool removes the subjective aspect of determining point clusters by assigning confidence values to each cell as either a significant hot spot, a nonsignificant spot, or a significant cold spot. Position data was divided into three timeframes: dredge working in lower area, dredge working in upper area, and no dredging operations.

Water quality. Water temperature plays an important role in influencing when ATS move upstream to spawn (Hilton at al. 2016). NOAA operates a water-quality buoy less than $2 \mathrm{~km}$ 
downstream of the study area that takes measurements every hour. These data are available online (https://buoybay.noaa.gov). Temperature data from July 20 to November 3 were downloaded, and hourly water temperature measurements were averaged to provide one measurement for each day.

\section{RESULTS AND DISCUSSION}

Dredging and water quality. Dredge operations started at 1500 on July 27, 2017. Dredging occurred in the lower dredge area from July 27 to August 23, and a final dredge pass-through was completed September 12-14. Dredging occurred in the upper dredge area from August 23 to September 12, with a final dredge pass through on September 15 and 16 (Figure 2). The dredge removed $278,056 \mathrm{~m}^{3}$ of sediment from the lower dredge area and $227,311 \mathrm{~m}^{3}$ from the upper dredge area (Figure 5).

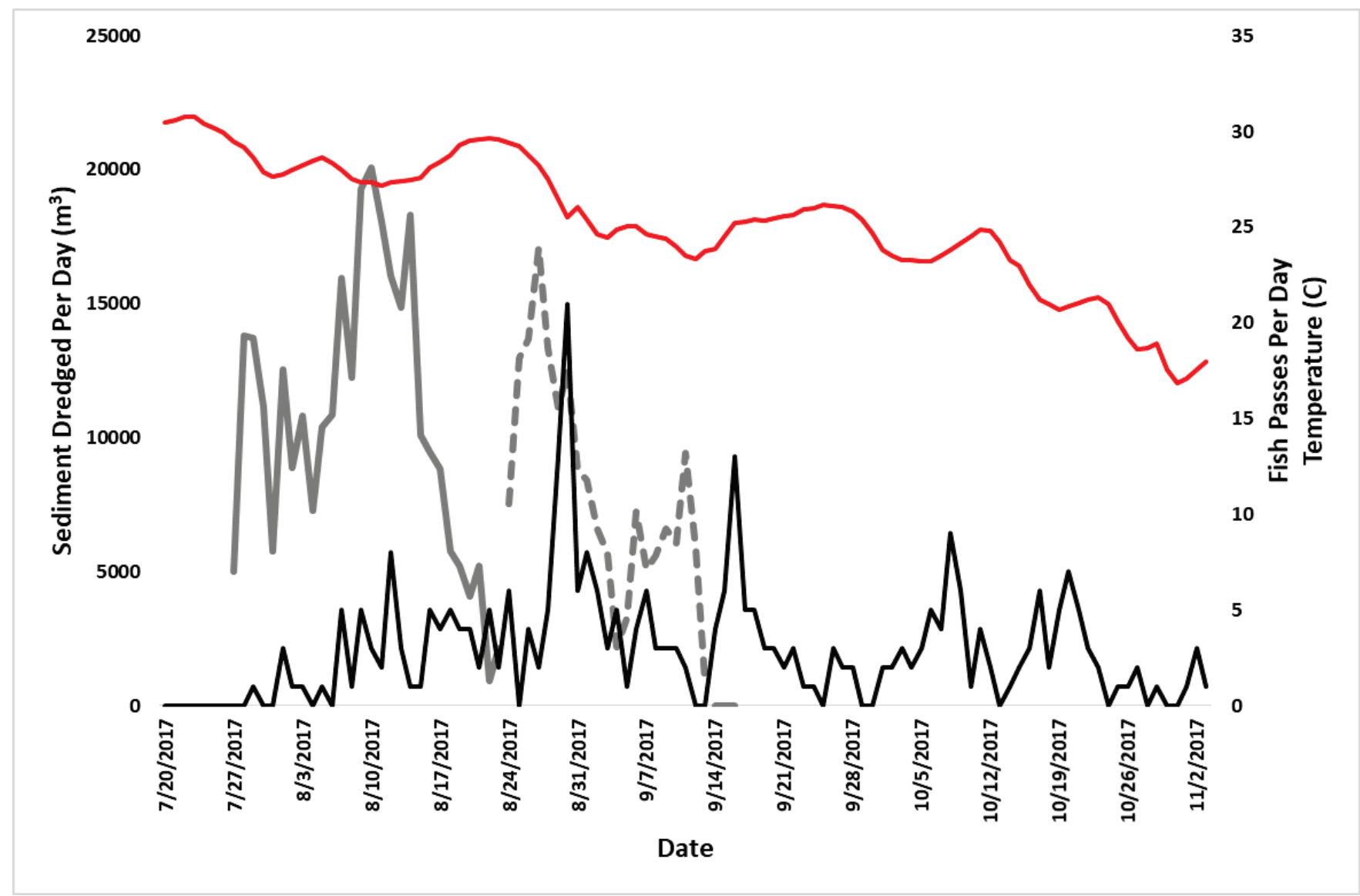

Figure 5. The primary $y$ axis shows how much sediment was dredged from the lower (solid gray line) and upper (dashed gray line) dredge areas. The secondary $y$ axis shows temperature (red line) and number of adult ATS moving past the dredge or through the area (black line) each day. Serendipitously, dredging started when water temperatures dropped to levels that trigger upstream spawning migrations.

Adult movements near dredging. A total of 110 tagged adult ATS entered the James River in 2017. Similar to previous years (Balazik, Garman, et al. 2012; Balazik and Musick 2015), a small proportion of tagged adults (4\%) did not migrate up the river for spawning but instead, remained in the lower Chesapeake Bay during the spawning season. During the study period, 106 
of the 110 telemetered adult ATS were detected, and fine-scale positions were determined for 99 adults, 7 females and 92 males. Accurate positions could not be determined for 7 males, but the dates they moved through the array are known.

Telemetry data indicate that no telemetered adults were entrained during dredging operations. Adults traversed the area quickly and therefore, sometimes passed through without accurate positions being generated. The VPS determined 5,839 positions for 99 adults (Figure 6). During dredging operations in the lower dredge area, 48 different adult ATS made a total of 88 passes by the dredge (Figures 5 and 7). Even though the VPS did not provide coverage for the upper dredge area, it can be determined whether a fish moved past the dredge when working in the upper area by combining detections from the VPS and the supplemental upstream gate (Figure 2). While the dredge was working in the upper area, 74 adults moved past the dredge a total of 129 times (Figures 5 and 7). After dredging finished on September 16,93 adults completely traversed the study area 125 times (Figures 5 and 7). No ATS that reached the study area while the dredge was working failed to move upstream past the dredge. Over half $(n=59,56 \%)$ of the spawning ATS made one pass by the dredge. Forty-four adults (41\%) passed the active dredge multiple times, with one ATS passing the dredge 13 times (Figure 7). If the active dredge and associated sound were a complete deterrent to ATS traversal, it is unlikely adult ATS would make repeated trips past the dredge. Three males never moved past the active dredge because they moved upstream in June and downstream in October, missing the dredge activity altogether (Figure 7).

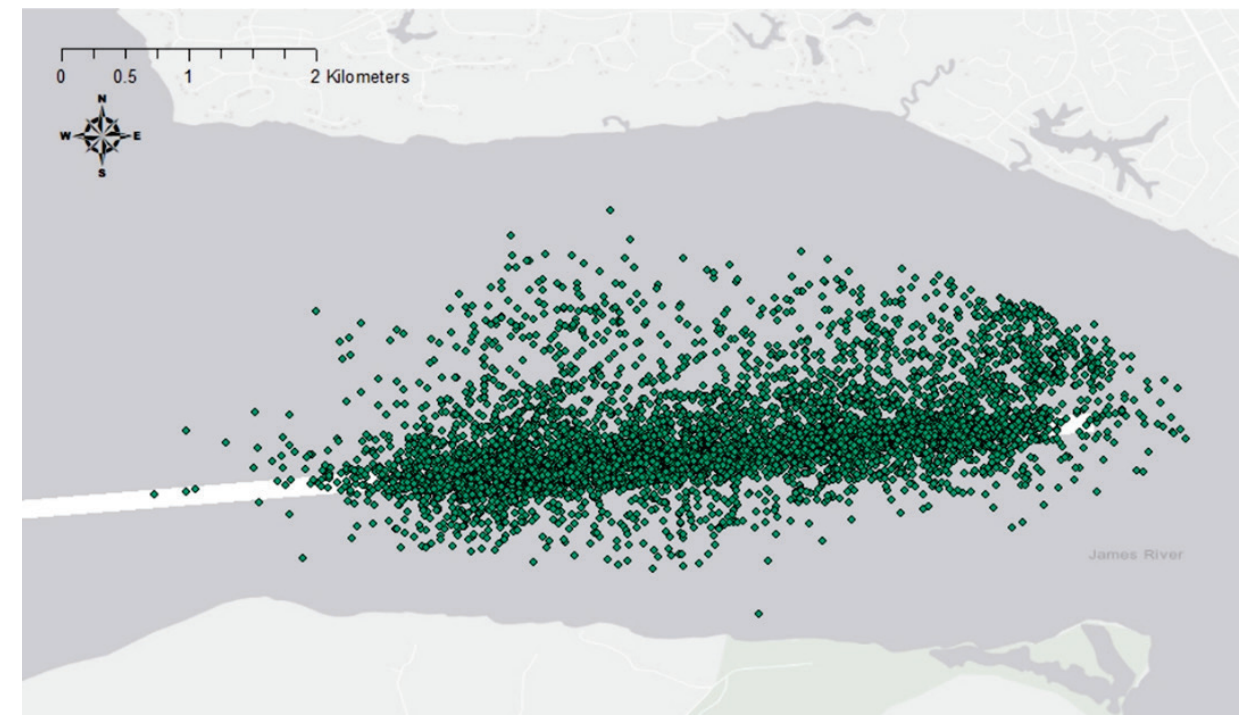

Figure 6. Points showing all adult ATS positions generated by the VPS array. In total, 99 adults were represented and 5839 positions recorded. 


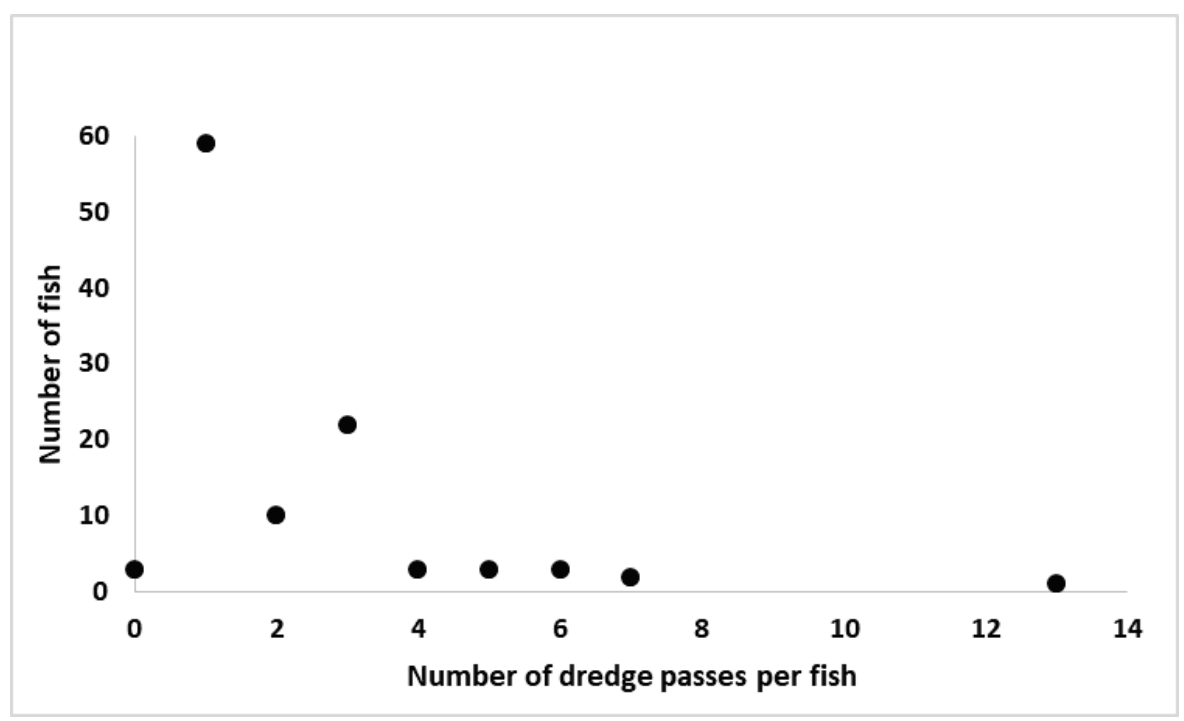

Figure 7. The number of times adult ATS moved past the cutterhead dredge Lexington.

As in previous years, the majority of adults started moving upstream when water temperatures in the lower river fell below $28^{\circ} \mathrm{C}$ (Balazik, unpublished data). Water temperatures fell below $28^{\circ} \mathrm{C}$ in the dredge area on July 30 (Figure 5). Most of the ATS staging downstream started migrating upstream to spawning habitat on July 29 when the dredge was working in the lower area. Adult activity gradually increased in the study area and then decreased as water temperatures began increasing around August 16 (Figure 5). Then, starting August 28, as water temperatures dropped relatively quickly to below $26^{\circ} \mathrm{C}$, upstream migration activity peaked while the dredge was working in the upper area (Figure 5). According to supplemental telemetry data from receivers close to spawning habitat, the peak spawning in 2017 occurred from September 5 to 14. When dredging operations were finishing in the upper area, there was a spike in migrating adults on September 15 as the postspawn ATS began to return to the ocean. Adults, mostly males, stay around spawning habitat for weeks after the peak spawning season, likely in an attempt to spawn with late-arriving females (Balazik, unpublished data). Adult males gradually left upstream spawning habitat in early October and migrated downstream to the ocean (Figure 5).

When the dredge was working in the lower and upper dredge areas, most of the adults were making upstream migrations to spawning habitat. Hot Spot Analysis showed adult positions were more densely packed in the immediate channel area during upstream and downstream migration (Figure 8). Adult positions in the lower dredge area were concentrated in the channel during upstream migration regardless of the presence or absence of an operating dredge in the immediate area, and ATS avoided areas away from the channel (Figure 8). During the downstream migration, adult ATS still had high densities in the channel but were more scattered throughout the study area compared to upstream migration positions (Figure 8). 

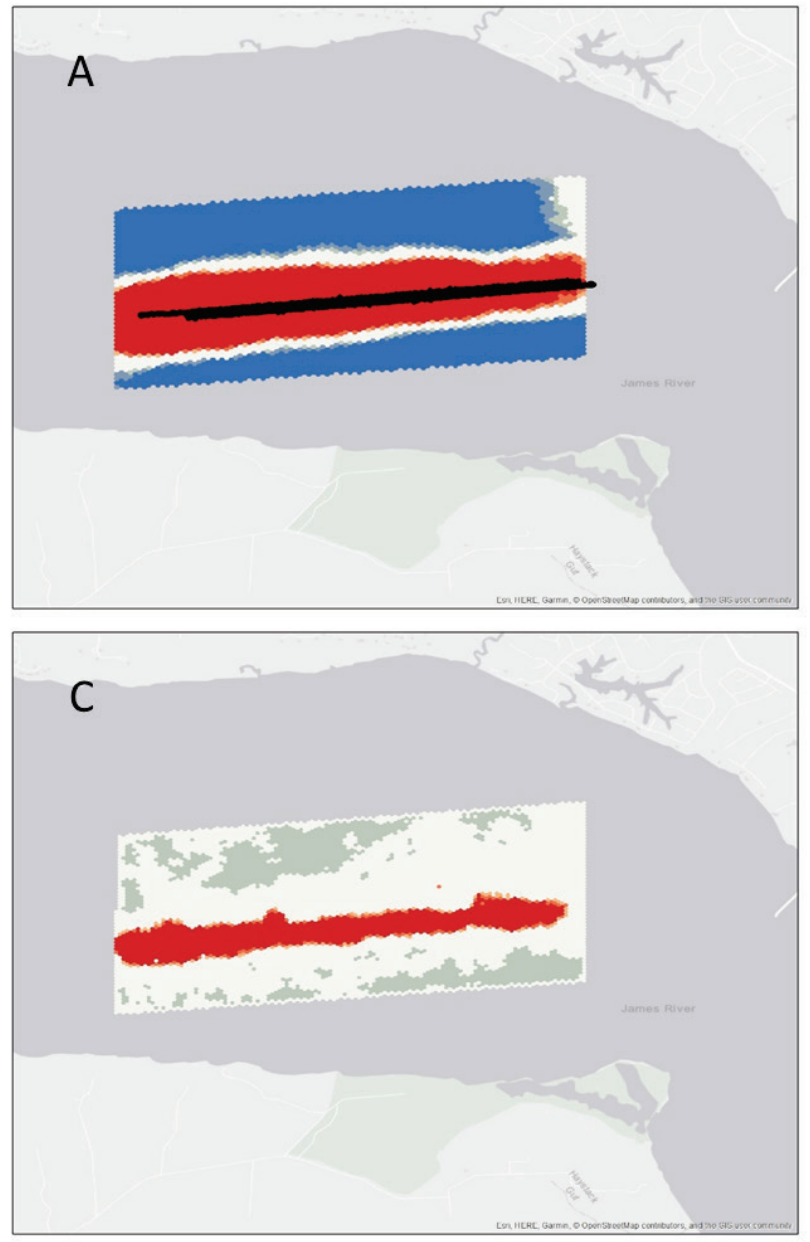

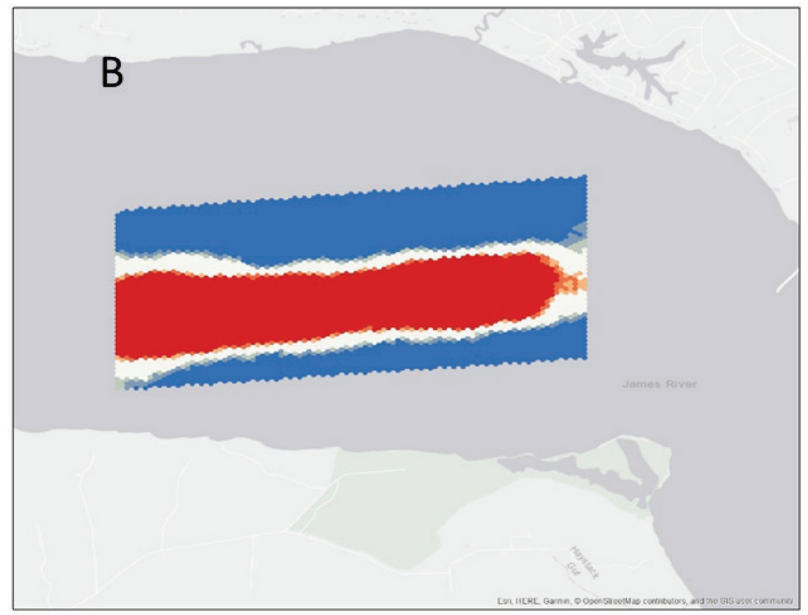

Cold Spot - $99 \%$ Confidence

Cold Spot - 95\% Confidence Cold Spot - $90 \%$ Confidence Not Significant

Hot Spot - $90 \%$ Confidence Hot Spot - 95\% Confidence

Hot Spot-99\% Confidence
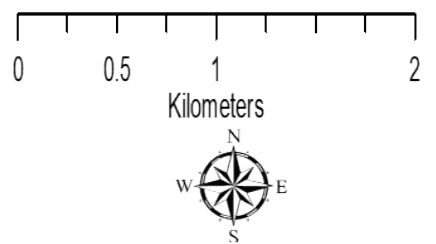

Figure 8. Hot Spot Analysis plots of adult ATS positions generated during the three different study periods: (A) active dredge working in the lower area (black dots refer to dredge positions), (B) active dredge working in the upper area, $(C)$ dredge inactive in upper or lower areas. All three plots show adult Atlantic sturgeon's preference to use the channel.

Although adults concentrated within the channel during upstream migration, it is unlikely that the dredge was attracting migrating adult ATS to the channel, but rather, the ATS naturally use the channel during upstream migration because of depth, current flow, or some other factors. Catch and telemetry data show migrating adults have a high affinity for deep channels (Balazik, Reine, et al. 2012; Balazik 2015), and results from this study suggest the preference continues even if dredging is occurring. Over the past five years, telemetered adult ATS have traversed active dredge operations hundreds of times in the James River, and data indicate that no mortalities of telemetered ATS resulted. The results of this study suggest that James River, Virginia, fall adult ATS are motivated to swim beyond and are not impeded by active cutterhead dredge operations.

\section{JUVENILE AND SUBADULT MOVEMENTS NEAR DREDGING}

Juveniles. The three telemetered juveniles were not detected near the dredging operation. One juvenile was positioned $20 \mathrm{~km}$ downstream of the study area, while the remaining fish were positioned over $40 \mathrm{~km}$ upstream of the study area. In the James River, juveniles tend to stay in 
deeper water most of the year, which is likely why they did not inhabit the study area during the study period (Matthew Balazik, Unpublished Data). Entrainment during riverine dredging has been discussed by managers as a possible threat to juvenile ATS survival. There is no evidence that entrainment of juvenile ATS occurs during riverine cutterhead dredging, but managers have not dismissed this potential impact. Further dedicated studies should evaluate this topic.

Subadults. During the study, 18 of the 60 tagged subadults detected in the river were detected in the VPS array for 3,548 positions (Figure 9). While dredging occurred in the lower dredge area, four subadults passed the dredge eight times. Eight subadults passed the dredge while working in the upper area a total of 18 times, as evident by the detection on the supplemental gate. In September after dredging was completed, 13 subadults made 43 passes through the study area.

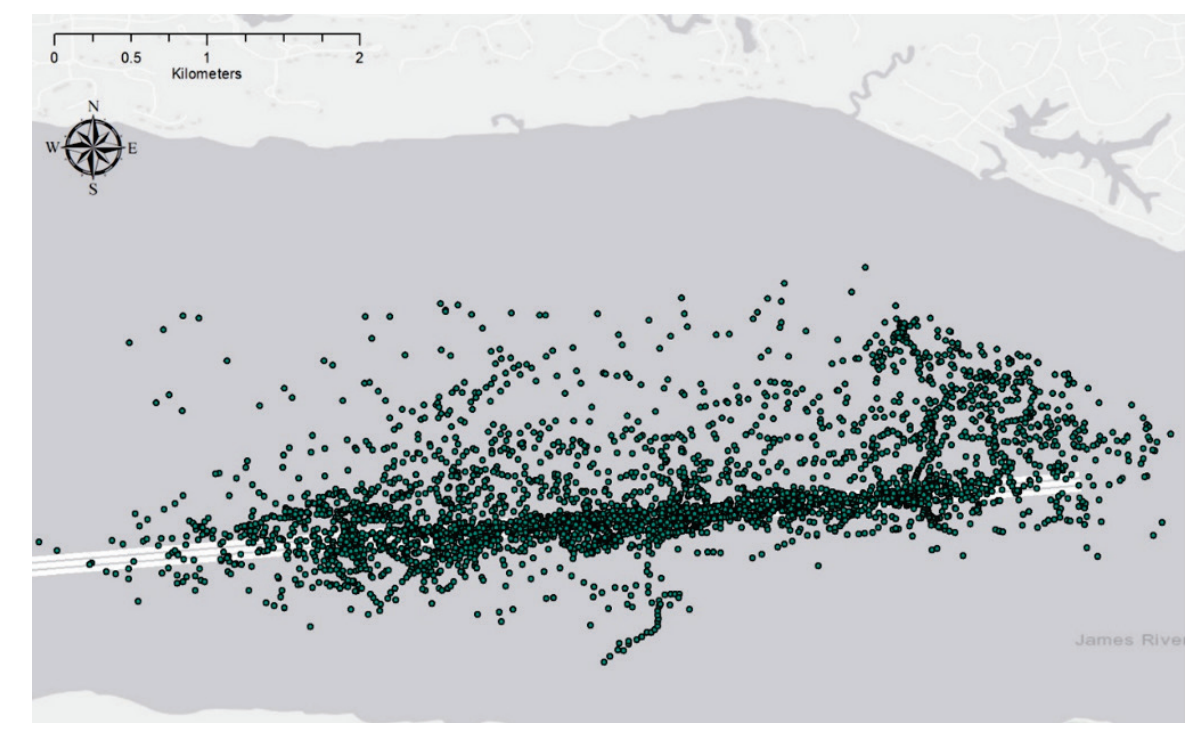

Figure 9. Points showing all subadult ATS positions generated by the VPS array for the lower dredge area.

The Optimized Hot Spot Analysis determined that the subadults in the lower dredge area had a high affinity for the channel even while the dredge was working (Figure 10). Only four subadults were detected in the array while the dredge was working in the lower dredge area, so Optimized Hot Spot Analysis during dredging classified most of the map as not significant. This classification does not provide much information, owing to the limited sample size (figure 10). It is worth noting that when the four subadult ATS were in the lower dredge area at the same time as the dredge, all the fish were in the channel where the dredge had operated a few days prior. Other studies suggest that subadult white sturgeon feed in recently dredged areas and sediment placement areas (Parsley, Popoff, and Romine 2011; Chapman et al. 2019). Considering feeding is the main activity associated with subadults during riverine residency, the data from this study suggest that subadults may be feeding in recently dredged areas. A similar pattern showing affinity for the channel was seen when the dredge was working in the upper area and when no dredge operations were occurring (Figure 10). 

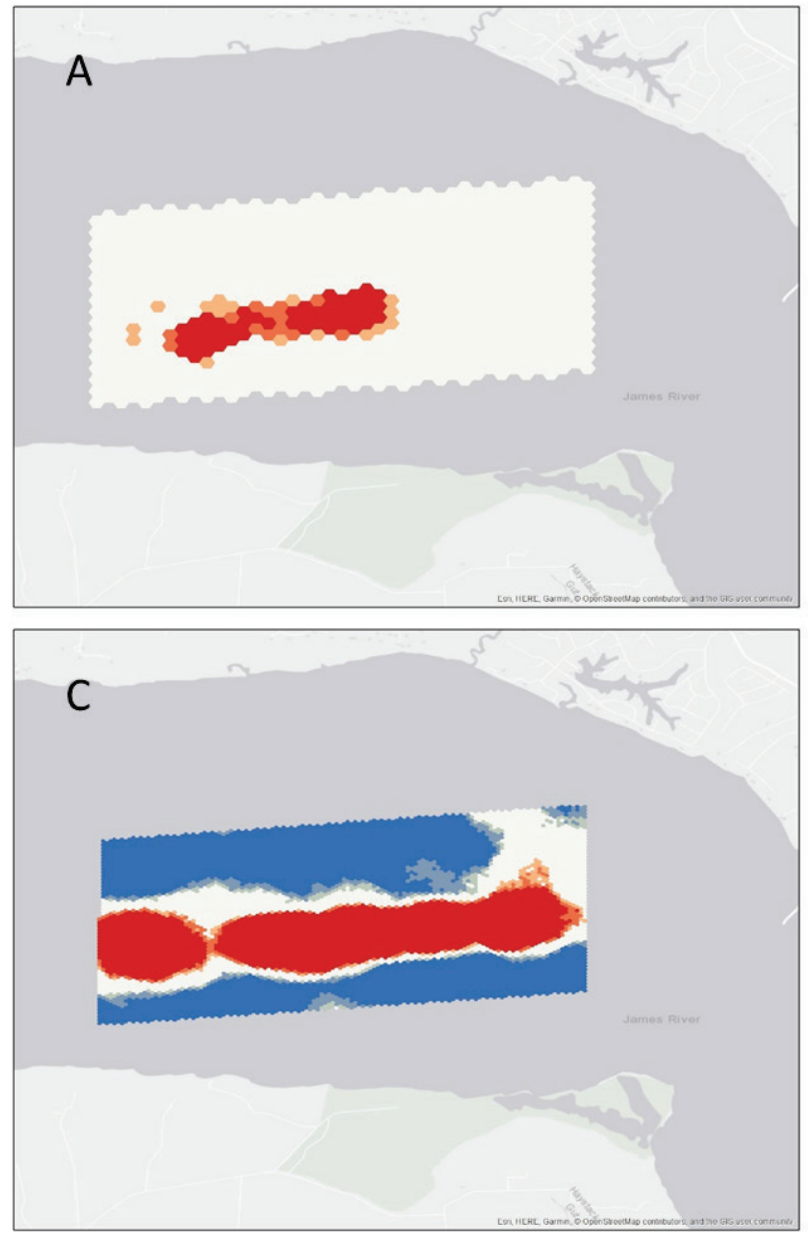

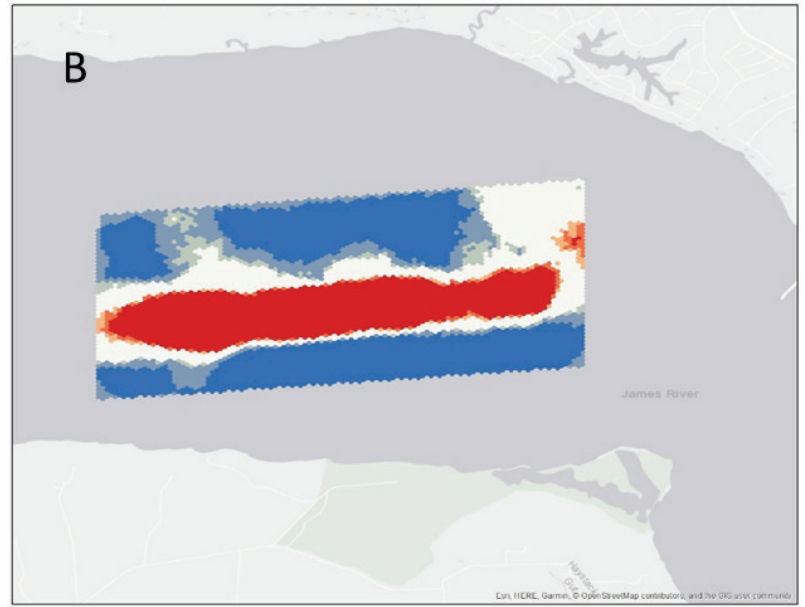

Cold Spot - 99\% Confidence Cold Spot - 95\% Confidence Cold Spot - $90 \%$ Confidence Not Significant
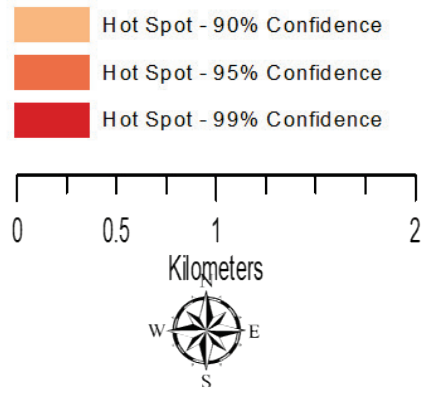

Figure 10. Hot Spot Analysis plots of subadult ATS positions generated during the thee different study periods: $(A)$ active dredge working in the lower area (dredge positions are not shown in panel A like in Figure 8 because the dredge points covered most of the hotspot data), (B) active dredge working in the upper area, $(C)$ dredge inactive in upper or lower areas. All three plots show subadult ATS prefer to inhabit the channel whether or not a dredge is working in the area.

CONCLUSIONS: This study sought to improve knowledge about the movement of ATS near a cutterhead dredge operating in the James River in Virginia. Adult and subadult ATS were successfully telemetered and tracked using VPS technology, resulting in fine-scale acoustic telemetry to identify ATS movement and location near a dredge operation. Adult and subadult ATS were positioned in the navigation channel most frequently, providing evidence for their affinity to use the channel while moving upstream or downstream past the dredge. The movement of adult ATS, particularly upstream past the dredge operation, suggests they are not prevented from reaching spawning habitat further upstream during the fall spawning migration. Additionally, no adult or subadult ATS were entrained by the dredge. The information generated by this field study could inform the decision on whether to expand the environmental window to protect ATS during the fall spawning migration.

With the exception of three years, hydraulic-cutterhead dredging has occurred in the James River during the summer and fall every year since 1998. While dredging is currently considered a major 
threat to recovery, the James River fall ATS population is estimated to be in the thousands and is possibly the most numerous population along its entire range. According to length at age frequencies, most of the current fall population was born after 1998 (Balazik, McIninch, et al. 2012), indicating that dredge operations did not stop spawning success in the past. Current collections of fall spawn young-of-year and age one ATS show that ATS are successfully spawning during dredge years, and passive telemetry shows adults moving past active dredges hundreds of times without any mortalities. The combined evidence of this study and past data suggests that the physical presence of a hydraulic-cutterhead dredge and associated underwater sounds during the spawning season does not hinder ATS spawning success or subadult feeding behavior in the lower James River.

POINTS OF CONTACT: For additional information, contact Dr. Matthew Balazik (601-6347445), Matthew.T.Balazik@usace.army.mil. This technical note should be cited as follows:

Balazik, Matthew T., Safra Altman, Kevin J. Reine, and Alan W. Katzenmeyer. 2021. Atlantic Sturgeon Movements in Relation to a Cutterhead Dredge in the James River, Virginia. DOER Technical Notes Collection. ERDC/TN DOER-R31. Vicksburg, MS: US Army Engineer Research and Development Center.

This technical note has been edited and reprinted from Matthew Balazik, Michael Barber, Safra Altman, Kevin Reine, Alan Katzenmeyer, Aaron Bunch, and Greg Garman, 2020, "Dredging Activity and Associated Sound Have Negligible Effects on Adult Atlantic Sturgeon Migration to Spawning Habitat in a Large Coastal River," PLOS One 15, no.3 (March): 1-13, https://doi.org/10.1371/journal.pone.0230029. Public Domain.

\section{REFERENCES}

ASSRT. 2007. Status review of Atlantic Sturgeon (Acipenser oxyrinchus oxyrinchus). Report to the National Marine Fisheries Service, Northeast Regional Office, February 23, 2007. 174 pp.

Balazik, M. T. 2015. "Capture and brief invasive procedures using electronarcosis does not appear to affect postrelease habits in male Atlantic sturgeon during the spawning season." North American Journal of Fisheries Management 35:398-402. doi:10.1080/02755947.2015.1011358

Balazik, M. T., D. J. Farrae, T. L. Darden, and G. C. Garman. 2017. Genetic differentiation of spring-spawning and fall-spawning male Atlantic sturgeon in the James River, Virginia. PLoS ONE 12(7): e0179661. doi:10.1371/journal. pone.0179661

Balazik, M. T., G. C. Garman, M. L. Fine, C. H. Hager, and S. P. McIninch. 2010. "Changes in age composition and growth characteristics of Atlantic sturgeon (Acipenser oxyrinchus oxyrinchus) over 400 years." Biology Letters 6(5):708-711. doi:10.1098/rsbl.2010.0144

Balazik, M. T., G. C. Garman, J. P. Van Eenennaam, J. Mohler, and L. C. Woods III. 2012. "Empirical evidence of fall spawning by Atlantic sturgeon in the James River, Virginia." Transactions of the American Fisheries Society 141: 1465-1471. doi:10.1080/00028487.2012.703157

Balazik, M. T., and J. A. Musick. 2015. "Dual annual spawning races in Atlantic sturgeon.” PloS ONE, 10, e0128234. doi:0128210.0121371/journal.pone.0128234.

Balazik, M. T., K. J. Reine, A. J. Spells, C. A. Fredrickson, M. L. Fine, G. C. Garman, and S. P. McIninch. 2012. “The potential for vessel interactions with adult Atlantic sturgeon in the James River, Virginia." North American Journal of Fisheries Management, 32:6, 1062-1069. doi:10.1080/0255947.2015.1011358. 


\section{ERDC/TN DOER-R31}

\section{September 2021}

Balazik, M. T., S. P. McIninch, G. C. Garman, and R. J. Latour. 2012. "Age and growth of Atlantic sturgeon in the James River, Virginia, 1997-2011." Transactions of the American Fisheries Society, 141:4, 1074-1080. doi:10.1080/00028487.2012.676590

Chapman, E., E. Miller, G. Singer, A. Hearn, M. Thomas, W. Brostaff, P. LaCivita, and A. Klimley. 2019. "Spatiotemporal occurrence of green sturgeon at dredging and placement sites in the San Francisco estuary." Environmental Biology of Fishes 102:27-40.

Farrae, D. J., W. C. Post, and T. L. Darden. 2017. "Genetic characterization of Atlantic sturgeon, Acipenser oxyrinchus oxyrinchus, in the Edisto River, South Carolina and identification of genetically discrete fall and spring spawning." Conservation Genetics 2017; 18:1-11. doi:10.1007/s10592-017-0929-7

Getis, A., and J. Ord. 1992. "The analysis of spatial association of distance statistics." Geographical Analysis 24:189206. doi:10.1111/j.1538-4632.1992.tb00261.x.

Hilton, E., B. Kynard, M. Balazik, A. Horodysky, and C. Dillman. 2016. "Review of the biology, fisheries, and conservation status off the Atlantic sturgeon, (Acipenser oxyrinchus oxyrinchus Mitchill, 1815)." Journal of Applied Ichthyology 32:30-66. doi:10.1111/jai.13242

Parsley, M., N. Popoff, and J. Romine. 2011. "Short-term response of subadult white sturgeon to hopper dredge disposal operations." North American Journal of Fisheries Management 31:1-11.

Reine, K., D. Clarke, M. Balazik, S. O’Haire, C. Dickerson, C. Frederickson, G. Garman, C. Hager, A. Spells, and C. Turner. 2014. Assessing impacts of navigation dredging on Atlantic sturgeon (Acipenser oxyrinchus). Technical Report ERDC/EL TR-1412. doi:10.13140/RG.2.1.5064.6565

Reine, K. J., D. D. Dickerson, and D. G. Clarke. 1998. Environmental windows associated with dredging operations. DOER Technical Notes Collection. ERDC TN DOER-E2. Vicksburg, MS: U.S. Army Engineer Research and Development Center. http://el.erdc.usace.army.mil/.

Roy, R., J. Beguin, C. Argillier, L. Tissot, F. Smith, S. Smedbol, and E. De-Oliveira. 2014. "Testing the VEMCO Positioning System: spatial distribution of the probability of location and the positioning error in a reservoir." Animal Biotelemetry 2:1. doi:10.1186/2050-3385-2-1

Smith, J. A., H. J. Flowers, and J. E. Hightower. 2015. "Fall spawning of Atlantic Sturgeon in the Roanoke River, North Carolina." Transactions of the American Fisheries Society 2015; 1: 48-54. doi:10.1080/00028487.2014.965344

USA Federal Register. 2012a. Endangered and threatened wildlife and plants: final listing for two distinct population segments of Atlantic Sturgeon (Acipenser oxyrinchus oxyrinchus) in the southeast. USA Fed Reg 77:5914-5982, 6 February 2012, 50 CFR Part 224.

USA Federal Register. 2012b. Endangered and threatened wildlife and plants; threatened and endangered status for distinct population segments of Atlantic Sturgeon in the Northeast. USA Fed Reg 77:5880-5912, 6 February 2012, 50 CFR Parts 223 and 224.

Vemco 2013 https://vemco.com/wp-content/uploads/2014/01/vps.pdf.

NOTE: The contents of this technical note are not to be used for advertising, publication, or promotional purposes. Citation of trade names does not constitute an official endorsement or approval of the use of such products. 